Universidade Tecnológica Federal do Paraná - UTFPR

Campus Ponta Grossa - Paraná - Brasil

ISSN: 1981-3686 / v. 02, n. 02: p. 42-59, 2008
Revista Brasileira deTecnologia

Agroindustrial

\title{
OTIMIZAÇÃO DE PROCESSAMENTO DE COBERTURA DE FRAMBOESA (Rubus idaeus) PELA ADIÇÃO DE AMIDO DE MILHO MODIFICADO E ÁCIDOS CÍTRICO E TARTÁRICO
}

\section{PROCESS OTIMIZATION FOR RASPBERRY (Rubus idaeus) TOPPING BY ADDITION OF MODIFIED CORN STARCH AND TARTARIC AND ACID CITRIC}

\author{
Elisabete Regina Braga Pereira ${ }^{1}$; Claire Tondo Vendruscolo ${ }^{2}$; Márcia Arocha Gularte ${ }^{3}$; Ricardo \\ Peraça Toralles ${ }^{4}$ \\ ${ }^{1,2,3}$ Universidade Federal de Pelotas - UFPel- Pelotas/RS- Brasil \\ ${ }^{4}$ Centro Federal de Educação Tecnológica - CEFET Pelotas/RS - Brasil \\ beterbpereira@ig.com.br
}

\begin{abstract}
Resumo
O objetivo deste trabalho foi otimizar um processo para a elaboração de cobertura de framboesa pela adição de amido de milho modificado e dos ácidos cítrico e tartárico. Foi realizado um delineamento composto central $2^{3}$, onde as variáveis dependentes estudadas foram cor, brilho, consistência e sabor, perfazendo um total de 20 ensaios. Foram também determinadas algumas características físicas e químicas da cobertura. Os atributos sensoriais foram avaliados por 2400 consumidores em potencial durante a $15^{a}$ Fenadoce (Feira Nacional do Doce) na cidade de Pelotas/RS. As diferentes combinações dos ácidos influenciaram nos resultados das características físicas e químicas das formulações testadas. Todas as formulações apresentaram excelente aceitação por parte dos consumidores, que apreciaram a cor e o brilho atrativos e o sabor agridoce que contrastou com o flan de baunilha, utilizado como veículo. O delineamento realizado estabeleceu que a melhor combinação entre as variáveis independentes testadas seria ácido cítrico 0,3 a 0,5\% e amido de milho modificado 4\%; que garantiria as características sensoriais desejadas e de qualidade do produto, viabilizando a sua comercialização.
\end{abstract}

Palavras chave: cobertura de framboesa; amido de milho modificado; ácidos.

\section{Introdução}

A framboesa (Rubus idaeus) é reconhecida pelo seu sabor doce e levemente ácido, cor atrativa e aroma peculiar. Caracteriza-se por ser um fruto agregado de 2,5 a $5 \mathrm{~g}$ em peso, com cultivares amarelas, pretas e as mais conhecidas de coloração vermelha (RASEIRA et al., 2004; STRIK, 2007). A grande aceitabilidade desta fruta, por parte dos consumidores, está relacionada não só às 
já citadas características sensoriais, mas também à sua composição química; sendo rica em vitamina C, carotenóides e compostos fenólicos, substâncias conhecidas como antioxidantes, a framboesa é considerada uma fruta muito saudável. Além disso, é fonte de carboidratos, minerais e vitaminas. Apresenta baixo conteúdo de caloria e gordura, mas é rica em fibras solúveis (BEATTIE et al., 2005; PANTELIDIS, et al., 2007; PLESSI, et al., 2007; TALCOTT, 2007).

Estudos indicam que a presença de compostos fenólicos em frutos como framboesa, mirtilo, amora-preta e morango proporcionam um efeito benéfico à saúde pela sua ação terapêutica, antiinflamatória e antioxidante, auxiliando no tratamento de algumas enfermidades como doenças coronarianas e o câncer (BEATTIE et al., 2005; BEEKWILDER et al., 2005). Algumas investigações demonstram uma grande diversidade na composição química e no poder antioxidante das frutas, dependendo entre outros condicionantes, da cultivar e do local de plantio (WANG \& LIN, 2000; HAFFNER, et al., 2002; ANTTONEN \& KARJALAINEN, 2005; CHUN, et al., 2006; MATTILA, et al., 2006), bem como do efeito do tempo e da temperatura de estocagem (GARCIAVIGUERA, 1999; OCHOA et al., 1999).

Como mudança nos hábitos de consumo e no intuito de suprir suas necessidades nutricionais e terapêuticas, a população brasileira incrementa sua alimentação com frutas, promovendo uma dieta balanceada e saudável (GONÇALVES et al., 2005). Frutas exóticas, praticamente desconhecidas da maioria da população, começam a ser cada vez mais divulgadas. Devido sua alta perecibilidade, a framboesa tem seu consumo in natura restrito a regiões mais próximas da produção, que no Brasil se concentra em micro regiões dos estados do Rio Grande do Sul, São Paulo e Minas Gerais; em um total de área estimada em 40 hectares (PAGOT e HOFFMANN, 2003; RASEIRA et al., 2004). Uma alternativa para os produtores é a industrialização, que além de aumentar o período de conservação, agrega valor à fruta. Desse modo, a framboesa pode ser comercializada na forma de doces, geléias e coberturas para sobremesa, a preços mais altos que a fruta in natura. A framboesa, devido sua cor e sabor agridoce se torna atrativa como cobertura para pudins, sorvetes, flan e tortas doces ou salgadas, possibilitando um efeito contrastante com agradável sensação ao paladar.

Segundo Rodrigues (2006), coberturas à base de frutas devem ser elaboradas pela cocção destas em uma mistura de água, espessante, açúcar e ácido. As frutas devem ser sadias, frescas ou congeladas. A cobertura deve apresentar textura firme o suficiente para não ser inteiramente adsorvida na superfície do produto; e sim escorrer parcialmente durante o consumo. A interação entre espessantes e ácidos proporciona uma estrutura com estabilidade física em função da viscosidade, e química devido à redução da atividade de água e do pH, além de preservar suas características sensoriais, fator relevante à aceitação do consumidor. Quando processada na forma de cobertura, a fruta apresenta-se dispersa em uma fase líquida viscosa e translúcida, sem alteração em sua cor, aroma e sabor. 
De acordo com a legislação, o amido é o produto amiláceo extraído das partes aéreas comestíveis dos vegetais. É composto basicamente por duas macromoléculas, amilose e amilopectina. A amilose é uma molécula linear formada por unidades de D-Glucose unidas entre si por ligações $\alpha$ 1-4 com um pequeno número de ramificações, enquanto que a amilopectina apresenta unidades ramificadas de D-Glucose unidas por ligações $\alpha 1-4$ e com 5 a $6 \%$ de ligações $\alpha$ 1-6 nos pontos de ramificação. A maioria dos amidos contém 20-30\% de amilose e 70-80\% de amilopectina, dependendo da fonte botânica (CEREDA, 2002 a).

Pela capacidade de dar corpo, promover viscosidade e melhora na textura, além de ser o espessante de menor custo, o amido de milho é mais utilizado na elaboração de produtos alimentícios como molhos, sopas e produtos de confeitaria. Se dispersa em água fria e tem sua viscosidade aumentada em temperaturas entre 60 e $70^{\circ} \mathrm{C}$, devido ao efeito do intumescimento. Entretanto, durante o resfriamento e ao longo do armazenamento as cadeias do amido tendem a interagir fortemente, através do rearranjo por pontes de hidrogênio, resultando em liberação de água (CEREDA, 2002 b). Em produtos como cobertura para sobremesa, em que uma elevada e estável viscosidade são necessárias, uma alternativa é a utilização de amido de milho modificado. Com a modificação a tendência à liberação de água no produto é reduzida. A modificação confere melhor textura e maior estabilidade ao longo do armazenamento (CEREDA et al., 2003).

Os ácidos apresentam a capacidade de comunicar e intensificar o sabor ácido de frutas. Sua ação contribui para uma maior conservação dos alimentos (GAVA, 1995), uma vez que reduz o pH do meio, inviabilizando a atividade microbiana. Promovem maior estabilidade física por prevenir reações oxidativas que resultam em alterações na cor e perda de aroma, além do potencial em ressaltar o sabor. Os ácidos orgânicos como o cítrico, presente em frutas como limão e laranja, e o tartárico, encontrado em uvas e tamarindo, apresentam uma sensação mais agradável ao palato. O ácido cítrico é bastante utilizado como acidulante, tamponante e flavorizante e possui solubilidade em água e etanol (ARAÚJO, 2004). O ácido tartárico é bastante utilizado nas indústrias de alimentos como acidulante, agente quelante e flavorizante (BURDOCK, 1997).

Os alimentos, em decorrência de diferentes condições de manipulação e preparo, podem sofrer alterações indesejáveis na sua estrutura, composição e características sensoriais. É importante estabelecer condições de processamento que garantam a conservação de alimentos e preservem suas características de qualidade e funcionalidade.

O objetivo desse estudo foi otimizar um processo para a elaboração de cobertura de framboesa pela adição de amido de milho modificado e os ácidos cítrico e tartárico, utilizando um delineamento composto central $2^{3}$ onde as variáveis respostas foram os atributos sensoriais cor, brilho, consistência e sabor, bem como determinar as características físicas e químicas. 


\section{Materiais e Métodos}

\subsection{Materiais}

Para a elaboração da cobertura foram utilizadas framboesas cultivadas na cidade de Vacaria/RS, safra 2006/2007 já selecionadas e mantidas congeladas $\left(-18^{\circ} \mathrm{C}\right)$, amido de milho modificado (SNOW FLAKE®6704) cedido pela CornProducts Brasil, ácido cítrico e tartárico (Labsynth).

\subsection{Métodos}

\subsubsection{Planejamento experimental}

A elaboração das coberturas de framboesa seguiu um delineamento fatorial completo $2^{3}$, incluindo 6 pontos axiais e 5 repetições no ponto central, totalizando 20 ensaios. As variáveis independentes estudadas foram as concentrações dos ácidos cítrico $\left(\mathrm{x}_{1}\right)$ e tartárico $\left(\mathrm{x}_{2}\right)$ e amido de milho modificado $\left(\mathrm{x}_{3}\right)$ em três níveis (tabela 1). As concentrações dos ácidos e amido de milho modificado utilizadas no delineamento foram estabelecidas de acordo com os limites permitidos na legislação brasileira para produtos alimentícios desse gênero (ANVISA).

Tabela 1. Variáveis reais e variáveis codificadas utilizadas no planejamento experimental

\begin{tabular}{|c|c|c|c|c|c|c|}
\hline \multirow[t]{3}{*}{ Formulação } & \multicolumn{6}{|c|}{ Variáveis Independentes } \\
\hline & \multicolumn{3}{|c|}{ Valores Codificados } & \multicolumn{3}{|c|}{ Valores Reais } \\
\hline & $\begin{array}{l}\text { Ácido cítrico } \\
\left(\mathrm{x}_{1}\right)\end{array}$ & $\begin{array}{l}\text { Ácido } \\
\text { tartárico } \\
\left(\mathrm{x}_{2}\right)\end{array}$ & $\begin{array}{l}\text { Amido de milho } \\
\text { modificado } \\
\left(\mathrm{x}_{3}\right)\end{array}$ & $\begin{array}{c}\text { Ácido cítrico } \\
(\%)\end{array}$ & $\begin{array}{c}\text { Ácido tartárico } \\
(\%)\end{array}$ & $\begin{array}{l}\text { Amido de milho } \\
\text { modificado } \\
(\%)\end{array}$ \\
\hline 1 & -1 & -1 & -1 & 0,11 & 0,11 & 1,62 \\
\hline 2 & -1 & -1 & 1 & 0,11 & 0,11 & 6,38 \\
\hline 3 & -1 & 1 & -1 & 0,11 & 0,39 & 1,62 \\
\hline 4 & -1 & 1 & 1 & 0,11 & 0,39 & 6,38 \\
\hline 5 & 1 & -1 & -1 & 0,39 & 0,11 & 1,62 \\
\hline 6 & 1 & -1 & 1 & 0,39 & 0,11 & 6,38 \\
\hline 7 & 1 & 1 & -1 & 0,39 & 0,39 & 1,62 \\
\hline 8 & 1 & 1 & 1 & 0,39 & 0,39 & 6,38 \\
\hline 9 & 1.682 & 0 & 0 & 0,5 & 0,25 & 4,0 \\
\hline 10 & -1.682 & 0 & 0 & 0 & 0,25 & 4,0 \\
\hline 11 & 0 & 1.682 & 0 & 0,25 & 0,5 & 4,0 \\
\hline 12 & 0 & -1.682 & 0 & 0,25 & 0 & 4,0 \\
\hline 13 & 0 & 0 & 1.682 & 0,25 & 0,25 & 8,0 \\
\hline 14 & 0 & 0 & -1.682 & 0,25 & 0,25 & 0 \\
\hline 15 & 0 & 0 & 0 & 0,25 & 0,25 & 4,0 \\
\hline 16 & 0 & 0 & 0 & 0,25 & 0,25 & 4,0 \\
\hline 17 & 0 & 0 & 0 & 0,25 & 0,25 & 4,0 \\
\hline 18 & 0 & 0 & 0 & 0,25 & 0,25 & 4,0 \\
\hline 19 & 0 & 0 & 0 & 0,25 & 0,25 & 4,0 \\
\hline 20 & 0 & 0 & 0 & 0,25 & 0,25 & 4,0 \\
\hline
\end{tabular}




\subsubsection{Processamento}

O processamento das formulações de cobertura de framboesa (tabela 1) foi realizado no laboratório de processamento do Departamento de Ciência dos Alimentos da Universidade Federal de Pelotas (DCA/UFPel), Pelotas/RS, seguindo o fluxograma da figura 1.

Utilizou-se fruta: sacarose: água na proporção 45:55:80 (p/p/v). A mistura amido de milho modificado (tabela 1), água e açúcar foi homogeneizada até completa dissolução e concentrada em tacho aberto, sob agitação até atingir $45^{\circ}$ Brix. Foram adicionadas as frutas, seguindo a concentração novamente até $45^{\circ}$ Brix. A seguir, adicionaram-se os ácidos e o produto foi homogeneizado durante 30 segundos. As formulações de cobertura de framboesa foram envasadas em potes de vidro com capacidade de $258 \mathrm{~mL}$ com tampas de metal, previamente esterilizadas; as embalagens com a cobertura foram submetidas a tratamento térmico $\left(100^{\circ} \mathrm{C}\right)$ em tacho aberto durante 15 minutos. Seguiu-se o resfriamento em água clorada a $25^{\circ} \mathrm{C}$ e o armazenamento em caixas de papelão em temperatura ambiente e procederam-se as avaliações.

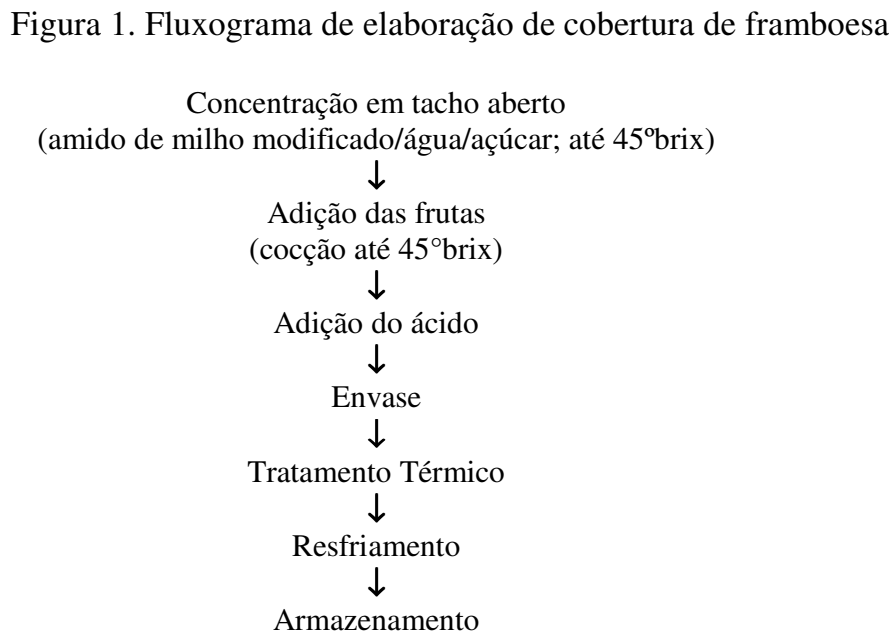

\subsubsection{Caracterização Físico-química da cobertura}

Todas as determinações físico-químicas foram realizadas de acordo com as normas da AOAC. 
a) os valores de $\mathrm{pH}$ das formulações foram determinados em potenciômetro digital (Digimed DM20) à temperatura de $25^{\circ} \mathrm{C}$;

b) os valores de sólidos solúveis totais ( ${ }^{\circ}$ Brix) foram determinados em refratômetro de mesa Abbé à temperatura de $20^{\circ} \mathrm{C}$;

c) a umidade foi determinada em estufa de secagem a $105^{\circ} \mathrm{C}$ até peso constante;

d) a acidez total titulável das formulações foi determinada através da titulação em $\mathrm{NaOH} 0,1 \mathrm{~N}$ de $1 \mathrm{~g}$ de amostra diluída em $50 \mathrm{~mL}$ de água destilada e expressa em porcentagem de ácido cítrico.

\subsubsection{Análise Instrumental de Cor}

A análise instrumental de cor foi realizada em colorímetro marca Minolta, modelo CR 300. O valor L* expressa a luminosidade e quanto mais perto de 100 , mais claro o produto. Os valores de $a^{*}$ indicam a tendência à coloração que vai de verde (-) a vermelha $(+)$; já os valores de $b^{*}$, tendência do azul (-) ao amarelo (+). A partir dos valores de $a^{*}$ e $b^{*}$, foram mensurados a saturação $\left(\mathrm{C}^{*}\right)$, que mede a intensidade da cor e o ângulo hue $\left(\mathrm{H}^{*}\right)$, que indica a tonalidade cromática (atributo em que a cor é percebida), através das fórmulas $\mathrm{C}^{*}=\left(\mathrm{a}^{*^{2}}+\mathrm{b}^{*^{2}}\right)^{1 / 2}$ e $\mathrm{H}^{*}=\operatorname{arc} \operatorname{tg}\left(\mathrm{b}^{*} / \mathrm{a}^{*}\right)$.

O aparelho foi calibrado com placa de azulejo branca padronizada pelo fabricante $(\mathrm{L}=97,06$; $a=0,26 ; b=1,83$ ); a seguir as amostras foram colocadas em placas de vidro transparente redonda com $6 \mathrm{~cm}$ de diâmetro e 1,5 cm de altura, para efetuar as leituras. As leituras foram realizadas em quintuplicata para cada formulação.

\subsubsection{Avaliação sensorial}

A avaliação sensorial com 2400 consumidores foi realizada durante a Feira Nacional do Doce (15 Fenadoce) na cidade de Pelotas/RS em 2007. Para a avaliação sensorial da cobertura de framboesa foi utilizado como veículo um flan sabor baunilha. A amostra de flan de baunilha com cobertura de framboesa foi servida em copos descartáveis de $50 \mathrm{~mL}$. Os consumidores foram convidados a fazer a avaliação sensorial e receberam junto com a amostra uma ficha de avaliação. Os atributos cor, brilho, consistência e sabor, foram avaliados através de escala hedônica estruturada de nove pontos (9-gostei muitíssimo, 5-nem gostei, nem desgostei, 1-desgostei muitíssimo) (GULARTE, 2002). 


\subsubsection{Análise Estatística}

Os resultados foram submetidos à análise de variância (ANOVA) e a verificação da significância da regressão e da falta de ajuste através do teste F, utilizando o programa software Statística (Statsoft v 7.0).

\section{Resultados e Discussão}

\subsection{Caracterização Físico-química}

As formulações de cobertura de framboesa foram avaliadas quanto ao $\mathrm{pH}$, acidez total titulável (ATT), sólidos solúveis totais (SST) e umidade, em triplicata, bem como a relação SST/ATT. As médias e desvios padrão das avaliações físico-químicas encontram-se na tabela 2.

Tabela 2. Médias e desvio padrão das avaliações físico-químicas de cobertura de framboesa*

\begin{tabular}{|c|c|c|c|c|c|}
\hline Formulações** & $\overline{\mathrm{pH}}$ & $\begin{array}{l}\text { Acidez total titulável } \\
\text { (\%ác. cítrico) }\end{array}$ & $\begin{array}{c}\text { Sólidos solúveis } \\
\text { totais }\left({ }^{\circ} \text { Brix }\right)\end{array}$ & Umidade (\%) & $\begin{array}{c}\text { Relação } \\
\text { SST/ATT }\end{array}$ \\
\hline 1 & $2,79^{\mathrm{b}} \pm 0,0$ & $0,81^{\mathrm{i}} \pm 0,0$ & $44,8^{\mathrm{abc}} \pm 0,28$ & $58,2^{\text {abcd }} \pm 0,81$ & $55,31^{\mathrm{e}}$ \\
\hline 2 & $2,81^{\mathrm{a}} \pm 0,01$ & $0,77^{\mathrm{j}} \pm 0,0$ & $43,3^{\mathrm{ef}} \pm 0,29$ & $55,6^{\mathrm{fgh}} \pm 0,13$ & $56,23^{\mathrm{c}}$ \\
\hline 3 & $2,58^{\mathrm{h}} \pm 0,01$ & $0,88^{\mathrm{h}} \pm 0,0$ & $45,5^{\mathrm{a}} \pm 0,0$ & $56.5^{\operatorname{defgh}} \pm 0,46$ & $51,70^{\mathrm{f}}$ \\
\hline 4 & $2,79^{\mathrm{b}} \pm 0,0$ & $0,95^{\mathrm{g}} \pm 0,0$ & $44,0^{\text {cde }} \pm 0,0$ & $55,1^{\mathrm{h}} \pm 1,23$ & $46,31^{\mathrm{g}}$ \\
\hline 5 & $2,65^{\mathrm{f}} \pm 0,01$ & $0,98^{\mathrm{f}} \pm 0,01$ & $45,0^{\mathrm{ab}} \pm 0,0$ & $57,4^{\text {abcde }} \pm 0,17$ & $45,92^{\mathrm{h}}$ \\
\hline 6 & $2,75^{\mathrm{c}} \pm 0,01$ & $1,01^{\text {cde }} \pm 0,01$ & $43,8^{\mathrm{def}} \pm 0,28$ & $55,2^{\mathrm{gh}} \pm 0,48$ & $43,36^{\mathrm{j}}$ \\
\hline 7 & $2,47^{\mathrm{j}} \pm 0,01$ & $1,03^{\mathrm{bc}} \pm 0,01$ & $45,0^{\mathrm{ab}} \pm 0,0$ & $55,7^{\text {abcd }} \pm 0,81$ & $43,69^{\mathrm{i}}$ \\
\hline 8 & $2,53^{\mathrm{i}} \pm 0,01$ & $1,05^{\mathrm{b}} \pm 0,01$ & $44,0^{\text {cde }} \pm 0,0$ & $58,6^{\mathrm{ab}} \pm 1,0$ & $41,90^{\circ}$ \\
\hline 9 & $2,60^{\text {gh }} \pm 0,01$ & $1,05^{\mathrm{b}} \pm 0,01$ & $44,0^{\text {cde }} \pm 0,0$ & $58,4^{\mathrm{abc}} \pm 0,14$ & $41,90^{\circ}$ \\
\hline 10 & $2,73^{\text {cde }} \pm 0,01$ & $0,69^{\mathrm{k} * * *} \pm 0,01$ & $44,3^{\text {bcd }} \pm 0,57$ & $58,7^{\mathrm{a}} \pm 0,41$ & $67,12^{\mathrm{a}}$ \\
\hline 11 & $2,47^{\mathrm{j}} \pm 0,01$ & $1,12^{\mathrm{a}} \pm 0,01$ & $45,3^{\mathrm{a}} \pm 0,57$ & $56,7^{\text {cdefg }} \pm 0,28$ & $40,80^{\mathrm{p}}$ \\
\hline 12 & $2,79^{\mathrm{ab}} \pm 0,01$ & $0,77^{\mathrm{j}} \pm 0,01$ & $44,8^{\mathrm{abc}} \pm 0,28$ & $56,7^{\text {cdefg }} \pm 0,43$ & $58,18^{\mathrm{b}}$ \\
\hline 13 & $2,70^{\mathrm{e}} \pm 0,01$ & $0,81^{\mathrm{i}} \pm 0,01$ & $45,0^{\mathrm{ab}} \pm 0,0$ & $55,8^{\text {efgh }} \pm 0,77$ & $55,55^{\mathrm{d}}$ \\
\hline 14 & $2,61^{\mathrm{g}} \pm 0,01$ & $1,13^{\mathrm{a}} \pm 0,01$ & $44,0^{\text {cde }} \pm 0,0$ & $57,9^{\text {abcd }} \pm 0,36$ & $38,93^{r}$ \\
\hline 15 & $2,74^{\mathrm{cd}} \pm 0,01$ & $1,02^{\text {cd }} \pm 0,02$ & $43,0^{\mathrm{f}} \pm 0,0$ & $56,9^{\text {cdefg }} \pm 0,54$ & $42,15^{\mathrm{Im}}$ \\
\hline 16 & $2,75^{\mathrm{c}} \pm 0,01$ & $1,0^{\mathrm{def}} \pm 0,01$ & $43,0^{\mathrm{f}} \pm 0,11$ & $57,1^{\text {bcdef }} \pm 0,11$ & $43,0^{\mathrm{k}}$ \\
\hline 17 & $2,71^{\mathrm{e}} \pm 0,01$ & $1,05^{\mathrm{b}} \pm 0,01$ & $42,0^{\mathrm{g}} \pm 0,0$ & $56,6^{\text {defgh }} \pm 0,26$ & $40,0^{\mathrm{q}}$ \\
\hline 18 & $2,74^{\mathrm{cd}} \pm 0,01$ & $1,0^{\mathrm{def}} \pm 0,01$ & $42,0^{\mathrm{g}} \pm 1,0$ & $57,0^{\text {bcdef }} \pm 0,24$ & $42,0^{\mathrm{mn}}$ \\
\hline 19 & $2,71^{\mathrm{e}} \pm 0,01$ & $1,0^{\mathrm{def}} \pm 0,01$ & $42,0^{\mathrm{g}} \pm 0,0$ & $56,8^{\text {cdefg }} \pm 0,52$ & $42,0^{\mathrm{mn}}$ \\
\hline 20 & $2,72^{\mathrm{de}} \pm 0,01$ & $0,99^{\mathrm{ef}} \pm 0,01$ & $41,8^{\mathrm{g}} \pm 0,2$ & $56,7^{\text {cdefg }} \pm 0,18$ & $42,22^{1}$ \\
\hline
\end{tabular}


Os valores de $\mathrm{pH}$ apresentaram diferença significativa, ficando entre 2,47 e 2,81. Foi observado que o incremento na concentração dos ácidos promoveu redução no pH. Por outro lado, as médias obtidas para acidez demonstraram que o incremento na concentração dos ácidos resultou em um aumento nos valores de acidez. Os valores encontrados para acidez apresentaram diferença significativa e ficaram entre 0,69 e 1,12. A acidez da formulação 10 foi expressa em \% de ácido tartárico, pois não foi adicionado ácido cítrico (tabela 1).

A adição dos ácidos em concentrações diferentes em toda a faixa estudada, contribuiu com a variação dos resultados na avaliação. Houve significativa correlação negativa $(\mathrm{p}<0,05)$ entre o pH e a acidez $(\mathrm{r}=-0,55)$, indicando que para valores menores de $\mathrm{pH}$ a acidez total titulável foi mais alta. Esses valores foram menores que os encontrados para a fruta in natura $(\mathrm{pH}=2,84$; acidez=1,78) antes do processamento. A escolha dos ácidos foi estabelecida previamente com o intuito de manter esses valores o mais próximo da fruta in natura (REDIES et al., 2006; VENDRUSCOLO et al., 2006).

Os sólidos solúveis totais ( ${ }^{\circ}$ Brix) apresentaram valores entre 41,8 e 45,3. A quantidade de açúcar adicionada nas formulações foi estabelecida em função dos sólidos solúveis médio da fruta ( ${ }^{\circ}$ Brix $\left.-9,8\right)$ e o teor de sólidos solúveis no produto final. Não houve correlação significativa de sólidos solúveis totais ( ${ }^{\circ}$ Brix) com pH e acidez total titulável.

Os valores de umidade variaram entre 55,1 e 58,7 apresentando diferença significativa. A umidade é um parâmetro de qualidade para os alimentos processados. O excesso de umidade favorece deteriorações no alimento influindo diretamente na sua conservação. RODRIGUES et al. (2007), encontraram valores de umidade em toppings de mirtilo elaborados com diferentes cultivares em torno de $60 \%$.

Os valores encontrados na relação SST/ATT variaram entre 38,93 e 67,12. Significativa correlação $(\mathrm{p}<0,05)$ negativa entre SST/ATT e acidez total titulável $(\mathrm{r}=-0,97)$ foi observada, e significa dizer que as formulações de cobertura de framboesa com menores concentrações de ácidos apresentaram maior relação SST/ATT, como ocorre nas formulações 10 e 12 . Não houve correlação significativa com $\mathrm{pH}(\mathrm{r}=0,39)$ e com sólidos solúveis totais ( $\left.{ }^{\circ} \mathrm{Brix}\right)(\mathrm{r}=0,41)$.

\subsection{Avaliação da Cor Instrumental}

As formulações de cobertura de framboesa foram avaliadas quanto aos parâmetros $L^{*}, a^{*}, b^{*}$, saturação $\left(\mathrm{C}^{*}\right)$ e o ângulo hue $\left(\mathrm{H}^{*}\right)$. Devido à coloração vermelha da framboesa, o valor do parâmetro $a^{*}$ (verde ao vermelho) é mais importante. Entretanto, ficou evidente que houve 
influência do parâmetro $b^{*}$ (azul ao amarelo), devido às diferenças significativas $(\mathrm{p}<0,05)$ apresentadas entre as formulações. As médias e desvios padrão da avaliação de cor instrumental encontram-se na tabela 3 .

Tabela 3. Médias e desvios padrão da avaliação de cor instrumental**

\begin{tabular}{|c|c|c|c|c|c|}
\hline \multirow{2}{*}{ Formulação*** } & \multicolumn{5}{|c|}{ Cor instrumental } \\
\hline & $\mathrm{L}^{*}$ & $a^{*}$ & $\mathrm{~b}^{*}$ & Chroma $\mathrm{C}_{\mathrm{ab}}$ & Ângulo hue $\mathrm{H}_{\mathrm{ab}}$ \\
\hline 1 & $15,4^{\mathrm{c}} \pm 0,77$ & $22,0^{\text {ef }} \pm 0,71$ & $-3,05^{\mathrm{gh}} \pm 0,91$ & $22,23 \pm 0,56$ & $-7,93 \pm 2,62$ \\
\hline 2 & $19,7^{\mathrm{a}} \pm 0,43$ & $25,2^{\mathrm{ab}} \pm 0,66$ & $1,25^{\mathrm{ab}} \pm 0,61$ & $25,25 \pm 0,7$ & $2,81 \pm 1,29$ \\
\hline 3 & $14,7^{\mathrm{c}} \pm 0,32$ & $21,6^{\mathrm{f}} \pm 0,82$ & $-4,15^{\mathrm{h}} \pm 0,52$ & $21,97 \pm 0,7$ & $-10,94 \pm 1,75$ \\
\hline 4 & $18,9^{\mathrm{a}} \pm 0,16$ & $26,5^{a} \pm 0,65$ & $1,48^{\mathrm{ab}} \pm 0,40$ & $26,53 \pm 0,67$ & $3,19 \pm 0,78$ \\
\hline 5 & $15,3^{\mathrm{c}} \pm 0,48$ & $22,8^{\text {cdef }} \pm 0,60$ & $-2,52^{\mathrm{fg}} \pm 0,70$ & $22,93 \pm 0,53$ & $-6,34 \pm 1,90$ \\
\hline 6 & $19,6^{\mathrm{a}} \pm 0,76$ & $26,2^{\mathrm{a}} \pm 0,81$ & $1,57^{\mathrm{a}} \pm 0,34$ & $26,29 \pm 0,82$ & $3,41 \pm 0,66$ \\
\hline 7 & $15,5^{\mathrm{c}} \pm 0,39$ & $22,0^{\mathrm{ef}} \pm 0,48$ & $-2,65^{\mathrm{fgh}} \pm 0,57$ & $22,19 \pm 0,42$ & $-6,87 \pm 1,58$ \\
\hline 8 & $19,8^{\mathrm{a}} \pm 0,93$ & $23,2^{\text {cdef }} \pm 0,51$ & $0,5^{\mathrm{abc}} \pm 0,98$ & $23,29 \pm 0,53$ & $1,19 \pm 2,37$ \\
\hline 9 & $17,3^{\mathrm{b}} \pm 0,16$ & $23,8^{\mathrm{bcd}} \pm 0,30$ & $-0,34^{\mathrm{cd}} \pm 0,37$ & $23,81 \pm 0,3$ & $-0,82 \pm 0,89$ \\
\hline 10 & $17,2^{\mathrm{b}} \pm 0,13$ & $23,0^{\text {cdef }} \pm 0,55$ & $-0,84^{\text {cde }} \pm 0,33$ & $22,99 \pm 0,54$ & $-2,10 \pm 0,84$ \\
\hline 11 & $17,1^{\mathrm{b}} \pm 0,22$ & $23,5^{\text {bcde }} \pm 0,15$ & $-0,72^{\text {cd }} \pm 0,23$ & $23,54 \pm 0,15$ & $-1,76 \pm 0,57$ \\
\hline 12 & $17,1^{\mathrm{b}} \pm 0,37$ & $22,6^{\mathrm{def}} \pm 0,36$ & $-1,4^{\mathrm{def}} \pm 0,52$ & $22,63 \pm 0,33$ & $-3,57 \pm 1,35$ \\
\hline 13 & $18,8^{\mathrm{a}} \pm 0,42$ & $23,1^{\text {cdef }} \pm 0,25$ & $-0,19^{\text {bcd }} \pm 0,27$ & $23,16 \pm 0,25$ & $0,31 \pm 0,57$ \\
\hline 14 & $15,1^{\mathrm{c}} \pm 0,77$ & $23,1^{\text {cdef }} \pm 1,09$ & $-2,35^{\mathrm{efgh}} \pm 1,26$ & $23,24 \pm 0,97$ & $-5,91 \pm 3,34$ \\
\hline 15 & $16,8^{\mathrm{b}} \pm 0,61$ & $24,3^{\text {bcd }} \pm 0,97$ & $-0,61^{\mathrm{cd}} \pm 0,75$ & $24,29 \pm 0,96$ & $-1,48 \pm 1,80$ \\
\hline 16 & $16,8^{\mathrm{b}} \pm 0,62$ & $24,2^{\text {bcd }} \pm 0,98$ & $-0,61^{\mathrm{cd}} \pm 0,75$ & $24,28 \pm 0,96$ & $-1,49 \pm 1,80$ \\
\hline 17 & $16,8^{\mathrm{b}} \pm 0,60$ & $24,3^{\mathrm{bcd}} \pm 0,97$ & $-0,59^{\text {cd }} \pm 0,74$ & $24,29 \pm 0,96$ & $-1,45 \pm 1,79$ \\
\hline 18 & $16,8^{\mathrm{b}} \pm 0,61$ & $24,1^{\text {bcd }} \pm 0,98$ & $-0,62^{\mathrm{cd}} \pm 0,76$ & $24,19 \pm 0,97$ & $-1,51 \pm 1,82$ \\
\hline 19 & $16,8^{\mathrm{b}} \pm 0,61$ & $24,3^{\text {bcd }} \pm 0,96$ & $-0,61^{\mathrm{cd}} \pm 0,75$ & $24,30 \pm 0,95$ & $-1,49 \pm 1,80$ \\
\hline 20 & $16,8^{\mathrm{b}} \pm 0,61$ & $24,3^{\mathrm{bc}} \pm 0,98$ & $-0,60^{\mathrm{cd}} \pm 0,76$ & $24,34 \pm 0,96$ & $-1,48 \pm 1,82$ \\
\hline
\end{tabular}

Os valores do parâmetro $L^{*}$ variaram entre 14,7 e 19,8 apresentando diferença significativa entre as formulações. Esses valores indicam pouca luminosidade e são menores que o da fruta in natura $\left(\mathrm{L}^{*}=31,26\right)$.

Em relação ao parâmetro a* os valores ficaram entre 21,6 e 26,5. As formulações $4\left(a^{*}=26,5\right)$ e $6\left(a^{*}=26,2\right)$ foram significativamente superiores e não apresentaram diferença entre si. Os valores encontrados nesse estudo foram menores que o da fruta in natura $\left(\mathrm{a}^{*}=37,39\right)$. Os valores de $\mathrm{C}^{*}$ variaram entre 21,99 e 26,54 .

Os valores de ângulo hue $\left(\mathrm{H}^{*}\right)$ apresentaram significativa correlação $(\mathrm{p}<0,05)$ positiva com os parâmetros $\mathrm{a}^{*}(\mathrm{r}=0,86)$ e $\mathrm{C}^{*}(\mathrm{r}=0,84)$. Esses resultados se contrapõem aos de LEE (2002), pois apresentaram uma correlação inversa entre esses parâmetros em diferentes variedades de laranja de polpa vermelha.

Houve significativa correlação $(\mathrm{p}<0,05)$ do parâmetro $b^{*}$ com $\mathrm{H}^{*}(\mathrm{r}=0,99), \mathrm{L}^{*}(\mathrm{r}=0,92), \mathrm{C}^{*}$ $(\mathrm{r}=0,85)$ e $\mathrm{a}^{*}(\mathrm{r}=0,86)$. Essa alta correlação indica forte interferência do parâmetro azul ( $\left.\mathrm{b}^{*}\right)$ na cor e intensidade, refletindo diretamente na saturação $\left(\mathrm{C}^{*}\right)$ e ângulo hue $\left(\mathrm{H}^{*}\right)$. O parâmetro $\mathrm{L}^{*}$ apresentou maior correlação $(\mathrm{p}<0,05)$ com $\mathrm{H}^{*}(\mathrm{r}=0,91)$ e menor com $\mathrm{a}^{*}(\mathrm{r}=0,66)$ e $\mathrm{C}^{*}(\mathrm{r}=0,64)$. 
A influência do espessante foi fortemente relacionada com a avaliação cromática, pois o incremento na concentração do amido de milho modificado, resultou em maiores valores para todos os parâmetros avaliados. Esses resultados são evidenciados pela significativa correlação $(\mathrm{p}<0,05)$ positiva do amido com os parâmetros $C^{*}(r=0,59), a^{*}(r=0,61), H^{*}(r=0,85), b^{*}(r=0,86)$ e $L^{*}(r=$ $0,94)$.

\subsection{Avaliação Sensorial}

Os atributos cor, brilho, consistência e sabor (tabela 4) foram avaliados por 2400 consumidores em potencial, onde $72,9 \%$ eram do sexo feminino e $27,1 \%$ do sexo masculino, com idades variando de 18 a 65 anos. Os consumidores ainda responderam o que mais gostaram e o que menos gostaram do produto.

Tabela 4. Médias e desvios dos atributos sensoriais avaliados nas formulações de cobertura de framboesa*

\begin{tabular}{ccccc}
\hline Formulação** & Cor & Brilho & Consistência & Sabor \\
\hline 1 & $8,4^{\mathrm{a}} \pm 0,69$ & $8,29^{\mathrm{ab}} \pm 0,87$ & $7,89^{\mathrm{a}} \pm 1,07$ & $8,48^{\mathrm{a}} \pm 0,81$ \\
2 & $8,28^{\mathrm{a}} \pm 0,75$ & $8,31^{\mathrm{ab}} \pm 0,83$ & $8,21^{\mathrm{a}} \pm 0,89$ & $8,46^{\mathrm{a}} \pm 0,75$ \\
3 & $8,41^{\mathrm{a}} \pm 0,73$ & $8,51^{\mathrm{a}} \pm 0,73$ & $8,07^{\mathrm{a}} \pm 1,00$ & $8,48^{\mathrm{a}} \pm 0,75$ \\
4 & $8,3^{\mathrm{a}} \pm 0,85$ & $8,21^{\mathrm{ab}} \pm 0,91$ & $8,16^{\mathrm{a}} \pm 0,93$ & $8,44^{\mathrm{ab}} \pm 0,72$ \\
5 & $8,54^{\mathrm{a}} \pm 0,68$ & $8,52^{\mathrm{a}} \pm 0,74$ & $8,14^{\mathrm{a}} \pm 0,90$ & $8,49^{\mathrm{a}} \pm 0,78$ \\
6 & $8,29^{\mathrm{a}} \pm 0,80$ & $8,32^{\mathrm{ab}} \pm 0,82$ & $8,25^{\mathrm{a}} \pm 0,95$ & $8,36^{\mathrm{abc}} \pm 0,86$ \\
7 & $8,35^{\mathrm{a}} \pm 0,72$ & $8,25^{\mathrm{ab}} \pm 0,77$ & $7,94^{\mathrm{a}} \pm 0,97$ & $8,31^{\mathrm{abcd}} \pm 0,83$ \\
8 & $8,39^{\mathrm{a}} \pm 0,80$ & $8,36^{\mathrm{ab}} \pm 0,73$ & $8,14^{\mathrm{a}} \pm 0,80$ & $8,18^{\mathrm{abcd}} \pm 0,99$ \\
9 & $8,23^{\mathrm{a}} \pm 0,73$ & $8,26^{\mathrm{ab}} \pm 0,80$ & $8,14^{\mathrm{a}} \pm 0,82$ & $8,13^{\mathrm{abcd}} \pm 0,98$ \\
10 & $8,13^{\mathrm{a}} \pm 0,80$ & $8,24^{\mathrm{ab}} \pm 0,82$ & $8,14^{\mathrm{a}} \pm 0,83$ & $8,44^{\mathrm{ab}} \pm 0,78$ \\
11 & $8,39^{\mathrm{a}} \pm 0,59$ & $8,41^{\mathrm{ab}} \pm 0,60$ & $8,27^{\mathrm{a}} \pm 0,76$ & $7,77^{\mathrm{d}} \pm 1,08$ \\
12 & $8,25^{\mathrm{a}} \pm 0,74$ & $8,28^{\mathrm{ab}} \pm 0,68$ & $7,95^{\mathrm{a}} \pm 0,88$ & $8,19^{\mathrm{abcd}} \pm 0,87$ \\
13 & $8,12^{\mathrm{a}} \pm 0,88$ & $8,09^{\mathrm{ab}} \pm 0,77$ & $7,88^{\mathrm{a}} \pm 0,89$ & $7,94^{\mathrm{abcd}} \pm 1,02$ \\
14 & $8,11^{\mathrm{a}} \pm 0,86$ & $8,04^{\mathrm{b}} \pm 0,93$ & $5,93^{\mathrm{b}} \pm 2,03$ & $7,97^{\mathrm{abcd}} \pm 1,07$ \\
15 & $8,26^{\mathrm{a}} \pm 0,75$ & $8,33^{\mathrm{ab}} \pm 0,66$ & $7,87^{\mathrm{a}} \pm 0,85$ & $7,86^{\mathrm{bcd}} \pm 1,07$ \\
16 & $8,25^{\mathrm{a}} \pm 0,76$ & $8,34^{\mathrm{ab}} \pm 0,65$ & $7,86^{\mathrm{a}} \pm 0,91$ & $7,85^{\mathrm{cd}} \pm 1,31$ \\
17 & $8,25^{\mathrm{a}} \pm 0,76$ & $8,34^{\mathrm{ab}} \pm 0,67$ & $7,85^{\mathrm{a}} \pm 0,93$ & $7,85^{\mathrm{cd}} \pm 1,41$ \\
18 & $8,25^{\mathrm{a}} \pm 0,76$ & $8,34^{\mathrm{ab}} \pm 0,67$ & $7,87^{\mathrm{a}} \pm 0,87$ & $7,86^{\mathrm{cd}} \pm 1,26$ \\
19 & $8,26^{\mathrm{a}} \pm 0,75$ & $8,33^{\mathrm{ab}} \pm 0,66$ & $7,86^{\mathrm{a}} \pm 0,94$ & $7,86^{\mathrm{bcd}} \pm 1,28$ \\
20 & $8,25^{\mathrm{a}} \pm 0,76$ & $8,34^{\mathrm{ab}} \pm 0,65$ & $7,85^{\mathrm{a}} \pm 0,87$ & $7,85^{\mathrm{cd}} \pm 1,17$ \\
\hline
\end{tabular}

* etras distintas na mesma coluna diferem entre si pelo teste de Tukey $(\mathrm{p}<0,05)$.

**percentuais de amido de milho modificado e ácidos cítrico e tartárico conforme tabela 1.

Em todas as formulações estudadas para o atributo cor sensorial não houve diferença significativa. Os valores médios encontrados ficaram entre 8,11 e 8,54, correspondendo aos termos hedônicos 8-gostei muito. $\mathrm{Na}$ maioria das formulações foi observado que o incremento na concentração de amido de milho modificado (níveis 0 e 1 ) resultou em menores valores na cor. $\mathrm{Na}$ formulação 13 (nível 1,682) essa redução foi maior.

Os valores encontrados para o atributo brilho ficaram entre 8,04 e 8,52. As formulações 3 e 5 foram significativamente superiores e não apresentaram diferença entre si. Também foram 
observados menores valores para este atributo com o incremento da concentração do amido. A significativa correlação $(\mathrm{p}<0,05)$ positiva com a cor $(\mathrm{r}=0,79)$ confirma esse comportamento.

Quanto à consistência, os valores médios ficaram entre 5,93 e 8,25. Com exceção da formulação 14 (sem amido), não houve diferença significativa entre as demais. Os valores médios corresponderam aos termos hedônicos 6-gostei ligeiramente e 8-gostei muito. Houve uma significativa correlação $(r=0,51)$ positiva entre a consistência e o amido de milho. Isto pode ser justificado pela capacidade do amido em dar corpo ao produto.

Por outro lado, a avaliação do sabor demonstra que os consumidores preferiram as formulações com concentrações de amido nos níveis -1 e 1. Cabe salientar que as formulações de cobertura de framboesa foram avaliadas utilizando como veículo um flan de baunilha. Desse modo fica evidente que a diferença nas médias em sabor, se deve a particular preferência do consumidor. Também foi observado que as formulações mais ácidas apresentaram menores valores nesse atributo. Os valores médios ficaram entre 7,77 e 8,49 com diferença significativa. As formulações 1,2 e 3 não apresentaram diferença significativa entre si e foram superiores as demais.

Quando questionados sobre o que mais gostou no produto, os consumidores apontaram a cor atrativa, o brilho e o sabor de uma doçura não enjoativa contrastando com o flan de baunilha. Entretanto para as formulações com menor concentração de amido foi mencionada por alguns consumidores que desgostaram da consistência mais fluída. A fluidez é indesejável, pois para coberturas a textura deve ser firme para permanecer na superfície do produto com a qual será consumida (RODRIGUES, 2006). A formulação $13 \mathrm{em}$ virtude da baixa espalhabilidade e as formulações 2, 9 e 10 pela percepção de sabor residual de maizena foram menos apreciadas por alguns consumidores.

\subsection{Correlação entre os atributos sensoriais, cor instrumental e características físico-químicas}

A relação entre os atributos sensoriais, parâmetros de cor e características físico-químicas através dos coeficientes de correlação calculados, estão na tabela 5.

Tabela 5. Coeficientes de correlação entre os atributos sensoriais, cor instrumental e características físico-químicas

\begin{tabular}{lcccc}
\hline & $\mathrm{pH}$ & Acidez total titulável & Sólidos solúveis totais $\left({ }^{\circ}\right.$ Brix $)$ & SST/ATT \\
\hline cor & $-0,31$ & 0,17 & 0,34 & $-0,16$ \\
brilho & $-0,15$ & 0,09 & - & $-0,13$ \\
consistência & 0,07 & $-0,31$ & 0,11 & 0,27 \\
sabor & 0,12 & $-0,53^{*}$ & $0,55^{*}$ & $0,57^{*}$ \\
$\mathrm{a}^{*}$ & $0,47^{*}$ & 0,19 & $-0,55^{*}$ & $-0,29$ \\
$\mathrm{~b}^{*}$ & 0,36 & 0,04 & $-0,42$ & $-0,11$ \\
$\mathrm{~L}^{*}$ & 0,27 & $-0,14$ & $-0,17$ & 0,10
\end{tabular}




\begin{tabular}{ccccc}
$\mathrm{H}^{*}$ & 0,35 & 0,05 & $-0,44$ & $-0,12$ \\
$\mathrm{C} *$ & $0,47 *$ & 0,19 & $-0,53 *$ & $-0,29$ \\
\hline \multicolumn{4}{c}{ *correlação significativa $(\mathrm{p}<0,05)}$.
\end{tabular}

Houve significativa correlação $(\mathrm{p}<0,05)$ do $\mathrm{pH}$ com o parâmetro $\mathrm{a}^{*}$ e a saturação $\left(\mathrm{C}^{*}\right)$. Essa correlação positiva foi evidenciada nas formulações onde os ácidos foram adicionados no nível 0 (ponto central) do delineamento, assim como nos níveis 0 e 1 de amido de milho modificado.

O sabor apresentou correlação $(\mathrm{p}<0,05)$ significativa com a acidez total titulável. O valor negativo indica uma correlação inversa, onde as maiores médias de acidez tiveram menor valor em sabor. Por outro lado a correlação significativa com os sólidos solúveis totais ( ${ }^{\circ}$ Brix) e com a relação SST/ATT foi positiva, indicando que valores mais altos em sabor foram acompanhados por maior ${ }^{\circ}$ Brix e relação SST/ATT. Essa correlação confirma a preferência dos consumidores por formulações menos ácidas e, portanto com a doçura mais perceptível.

Os sólidos solúveis totais $\left({ }^{\circ}\right.$ Brix $)$ apresentaram significativa correlação $(\mathrm{p}<0,05)$ negativa com o parâmetro a* e $C^{*}$.

Os parâmetros de cor objetiva não apresentaram correlação $(\mathrm{p}<0,05)$ significativa com os atributos sensoriais. Entretanto, pelos valores médios encontrados na avaliação de cor sensorial indicam correlação inversa com os valores de $\mathrm{L}^{*}, \mathrm{a}^{*}, \mathrm{~b}^{*}, \mathrm{C}^{*} \mathrm{e} \mathrm{H}^{*}$.

\subsection{Efeito combinado da adição de amido de milho modificado e ácidos cítrico e tartárico nos} atributos sensoriais da cobertura de framboesa

As estimativas dos efeitos linear, quadrático e de interação dos atributos sensoriais cor, brilho, consistência e sabor em relação ao erro puro, estão nas figuras 2 e 3 .

Figura 2. Gráfico de pareto para os efeitos dos atributos sensoriais cor (a) e brilho (b) de cobertura de framboesa

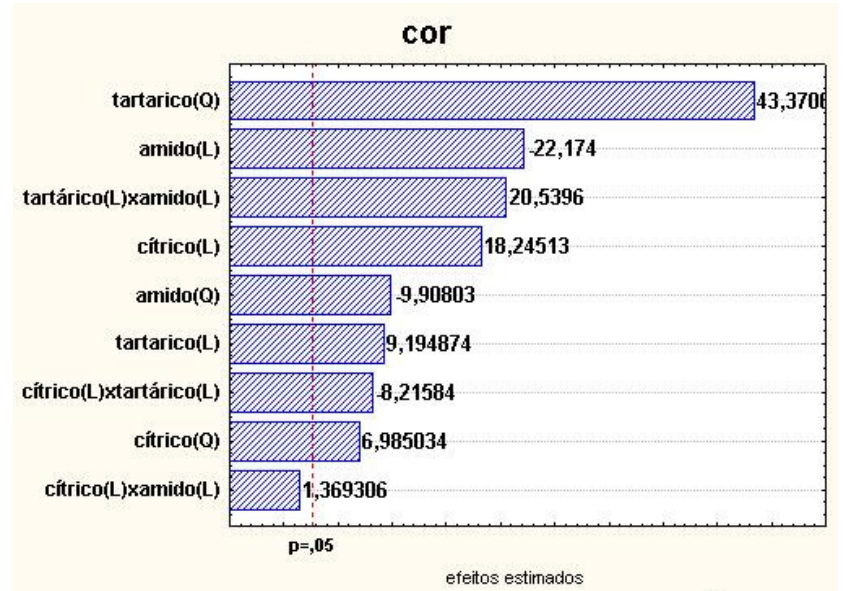

(a)

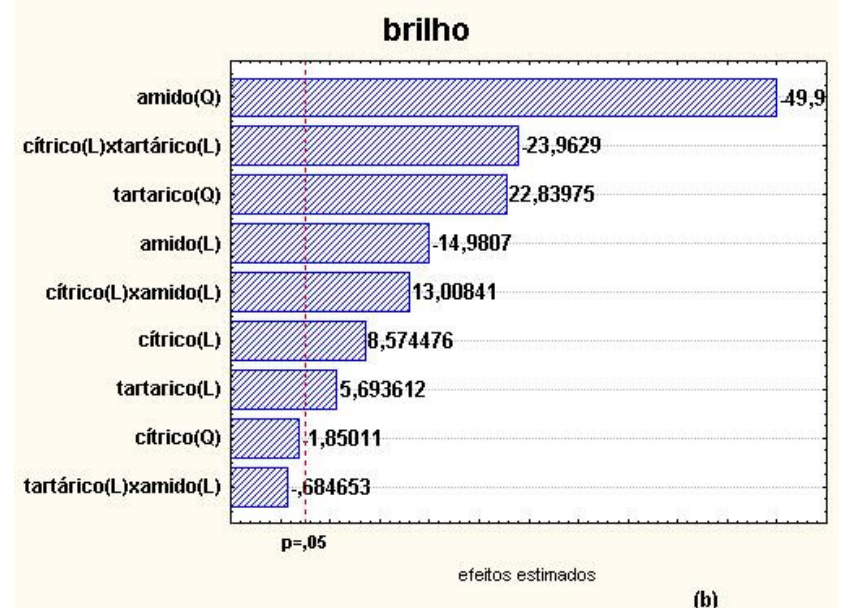

(b) 
Os efeitos estimados indicam a influência de cada variável na resposta. Para o atributo cor (figura 2a) apenas o efeito da interação ácido cítrico/amido de milho modificado não apresentou significância estatística a 95\% de confiança. O efeito quadrático do ácido tartárico apresentou maior influência para o atributo cor. Por outro lado o valor negativo do efeito linear do amido demonstra que o aumento da sua concentração reduziu os valores da cor sensorial.

Quanto ao brilho (figura 2b) a interação ácido tartárico/amido de milho modificado não foi significativo. O amido de milho modificado (Q) teve maior influência na resposta e com valor negativo. Entretanto, a consistência (figura 3a) teve influência maior e positiva do efeito linear do amido, indicando que o aumento nesta variável aumentou a resposta; para esse atributo todos os efeitos apresentaram significância a 95\% de confiança.

Para a resposta sabor (figura 3b), o efeito da interação ácido tartárico x amido de milho modificado não foi significativo a $95 \%$ de confiança. O efeito que mais contribui com a resposta foi o ácido cítrico (Q). Entretanto os valores negativos entre os efeitos lineares significam que o incremento de suas concentrações resultou em menor resposta para o atributo. A maior influência negativa na resposta foi do ácido tartárico.

Figura 3. Gráfico de pareto para os efeitos dos atributos sensoriais consistência (a) e sabor (b) de cobertura de framboesa

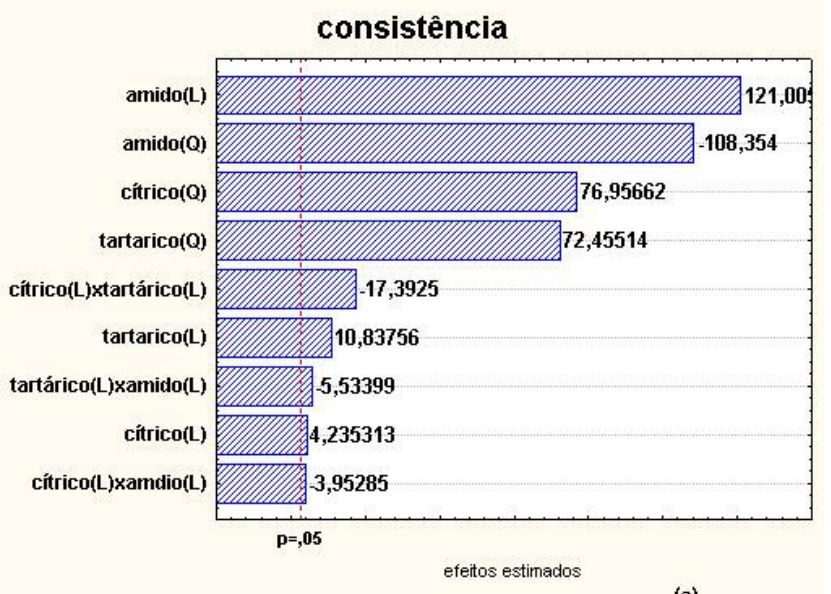

(a)

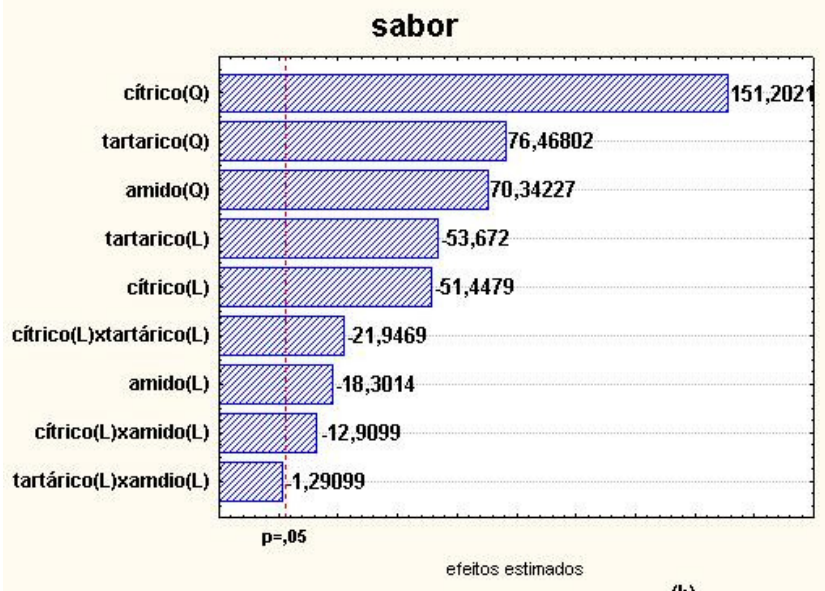

(b)

Os coeficientes de regressão, determinação $\left(\mathrm{R}^{2}\right)$ e valores de $\mathrm{F}$ do modelo ajustado para os atributos sensoriais estudados, estão na tabela 6 .

Tabela 6. Coeficientes de regressão, de determinação $\left(\mathrm{R}^{2}\right)$ e valores de $\mathrm{F}$ do modelo ajustado para as variáveis cor, brilho, consistência e sabor*

\begin{tabular}{ccccc}
\hline Coeficiente & \multicolumn{4}{c}{ Valores $^{\mathrm{b}}$} \\
\hline & cor & brilho & consistência & sabor \\
\hline Intercepta $\left(\mathrm{b}_{0}\right)$ & $8,248 \pm 0,054$ & $8,330 \pm 0,0046$ & $7,847 \pm 0,0093$ & $7,845 \pm 0,0057$ \\
Lineares & & & & \\
$\mathrm{x}_{1}\left(\mathrm{~b}_{1}\right)$ & $0,025 \pm 0,0036$ & $0,012 \pm 0,0036$ & $0,010 \pm 0,0062$ & $-0,076 \pm 0,0038$ \\
$\mathrm{x}_{2}\left(\mathrm{~b}_{2}\right)$ & $0,013 \pm 0,0036$ & $0,008 \pm 0,0036$ & $0,026 \pm 0,0062$ & $-0,079 \pm 0,0038$ \\
\hline
\end{tabular}




\begin{tabular}{ccccc}
\hline $\mathrm{x}_{3}\left(\mathrm{~b}_{3}\right)$ & $-0,031 \pm 0,036$ & $-0,021 \pm 0,0036$ & $0,293 \pm 0,0062$ & $-0,027 \pm 0,0038$ \\
Quadráticos & & & & \\
$\mathrm{x}_{1} \mathrm{x}_{1}\left(\mathrm{~b}_{11}\right)$ & $0,009 \pm 0,0035$ & - & $0,181 \pm 0,0061$ & $0,218 \pm 0,0037$ \\
$\mathrm{x}_{2} \cdot \mathrm{x}_{2}\left(\mathrm{~b}_{22}\right)$ & $0,059 \pm 0,0035$ & $0,031 \pm 0,0034$ & $0,170 \pm 0,0061$ & $0,110 \pm 0,0037$ \\
$\mathrm{x}_{3} \cdot \mathrm{x}_{3}\left(\mathrm{~b}_{33}\right)$ & $-0,013 \pm 0,0035$ & $-0,067 \pm 0,0034$ & $-0,255 \pm 0,0061$ & $0,101 \pm 0,0037$ \\
Interações & & & & \\
$\mathrm{x}_{1} \mathrm{x}_{2}\left(\mathrm{~b}_{12}\right)$ & $-0,015 \pm 0047$ & $-0,043 \pm 0,0047$ & $-0,055 \pm 0,0081$ & $-0,043 \pm 0,0049$ \\
$\mathrm{x}_{1} \mathrm{x}_{3}\left(\mathrm{~b}_{13}\right)$ & - & $0,024 \pm 0,0047$ & $-0,013 \pm 0,0081$ & $-0,025 \pm 0,0049$ \\
$\mathrm{x}_{2} \mathrm{x}_{3}\left(\mathrm{~b}_{23}\right)$ & $0,038 \pm 0047$ & - & $-0,018 \pm 0,0081$ & - \\
\hline $\mathrm{R}^{2}$ & 0,4387 & 0,4742 & 0,7068 & 0,7593 \\
Fcalculado & 1,08 & 1,54 & 2,68 & 4,33 \\
Ftabelado & 2,95 & 2,91 & 3,02 & 2,95 \\
\hline
\end{tabular}

Para as respostas consistência e sabor os coeficientes de determinação $\left(\mathrm{R}^{2}\right)$ foram maiores que 0,70. O modelo polinomial para o atributo sabor foi preditivo, mas o valor de $\mathrm{F}$ calculado foi de apenas 1,47 vezes maior que o tabelado. Entretanto para a resposta consistência o modelo não foi preditivo, uma vez que o valor de $\mathrm{F}$ calculado foi menor que o $\mathrm{F}$ tabelado, evidenciando a falta de ajuste (NETO et al., 2007).

Os coeficientes de determinação $\left(\mathrm{R}^{2}\right)$ para as respostas sensoriais cor e brilho foram menores que 0,50 , demonstrando que o modelo polinomial não foi significativo. Os valores de $\mathrm{F}$ tabelado foram pelo menos 2 vezes maiores que o $\mathrm{F}$ calculado, confirmando que o modelo não é preditivo.

Após avaliação dos dados por regressão não linear foram gerados os modelos para os atributos sensoriais cor, brilho, consistência e sabor de acordo com as equações 1, 2, 3 e 4 como função das variáveis significativas.

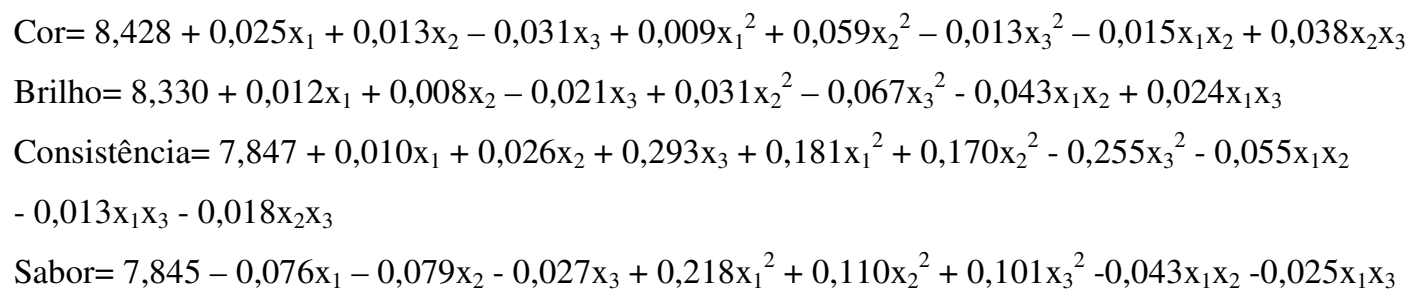

A partir das equações geradas foi feita uma análise para estabelecer as melhores condições de processamento de cobertura de framboesa para todas as formulações estudadas. Para reproduzir os resultados a concentração de amido de milho modificado $\left(\mathrm{x}_{3}\right)$ foi fixada no nível 0 (ponto central do delineamento) e estão representados nas figuras 4 e 5 .

Figura 4. Efeito interativo das variáveis ácido cítrico, ácido tartárico e amido de milho modificado a $4 \%$ na cor (a) e brilho (b) de cobertura de framboesa 

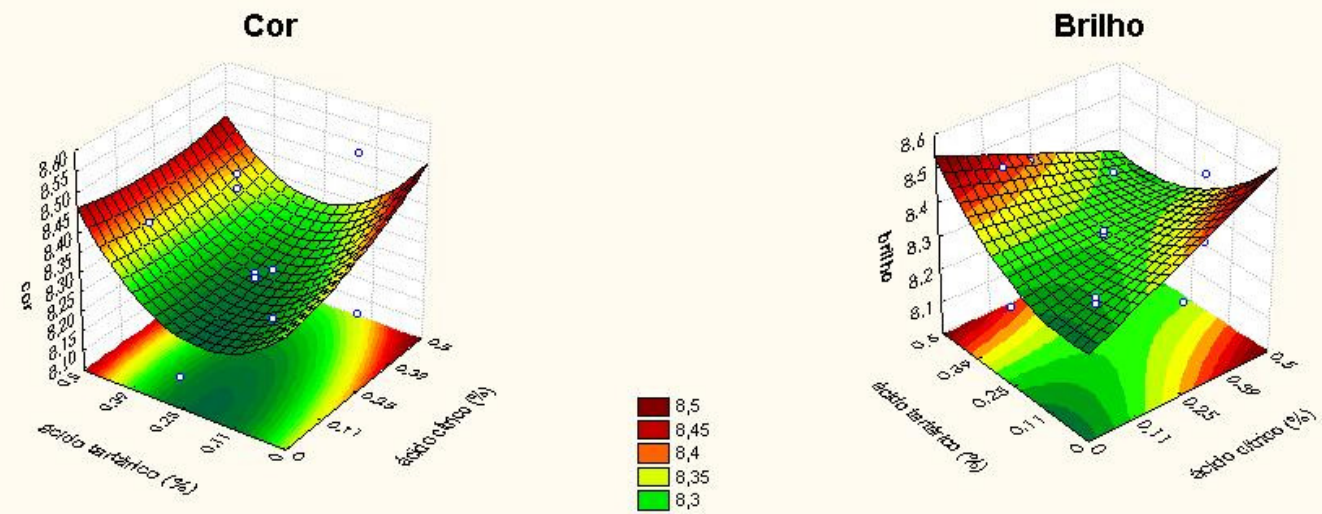

(a)

(b)

A superfície de resposta para o atributo cor demonstra que para qualquer concentração de ácido cítrico, a adição de ácido tartárico deve ficar em torno de 0,5\% (valor máximo). Entretanto a inclinação da superfície indica melhores resultados somente com a adição de ácido cítrico.

Em relação ao brilho (figura 4b) as formulações em que os ácidos foram combinados entre os níveis -1 e 1 não influenciou na resposta, pois a inclinação aponta para concentrações em torno de 0,5\% de um ou outro. Pela curvatura os melhores resultados são para a adição de ácido cítrico. A superfície de resposta para o atributo consistência (figura 5a), apresenta o mesmo comportamento.

Figura 5. Efeito interativo das variáveis ácido cítrico, ácido tartárico e amido de milho modificado a $4 \%$ na consistência (a) e sabor (b) de cobertura de framboesa

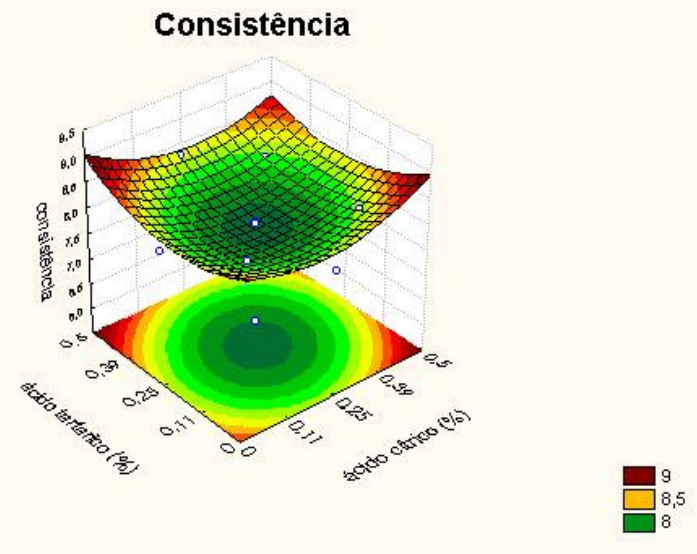

(a)

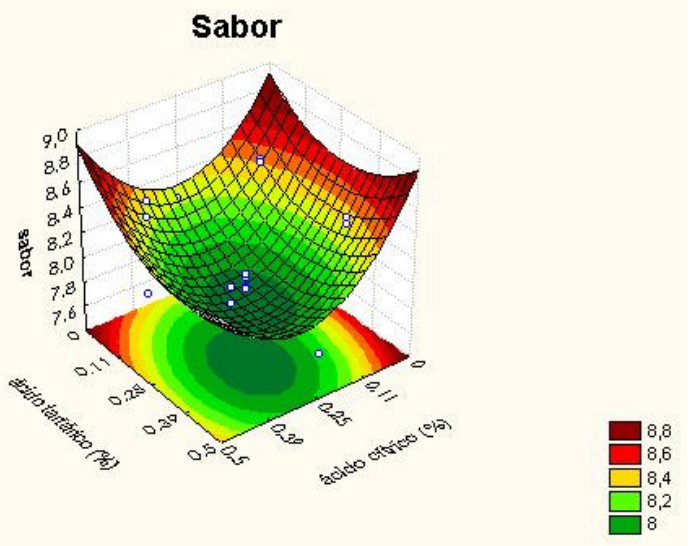

(b)

A superfície de resposta para o atributo sabor indica que o aumento na concentração dos ácidos não influenciou na resposta. A influência maior está na adição de um ou outro ácido no nível 1,682 (0,5\%). O caminho de máxima inclinação indica melhores resultados para a adição de ácido cítrico entre 0,3 e $0,5 \%$.

\section{Conclusão}


O delineamento realizado estabeleceu que a melhor combinação entre as variáveis independentes testadas seria ácido cítrico 0,3 a $0,5 \%$ e amido de milho modificado 4\%; que garantiria as características sensoriais desejadas e de qualidade do produto, viabilizando a sua comercialização. Os modelos quadráticos se ajustaram melhor as variáveis dependentes estudadas, com influência maior do amido de milho modificado. Nesta otimização de processo, todas as formulações apresentaram excelente aceitação pelos consumidores, em parte devido às excepcionais características sensoriais da framboesa. Foram apreciadas, em sua maioria, pela cor e brilho atrativos e sabor agridoce agradável ao paladar.

\begin{abstract}
The research aimed to optimize a process for the preparation of topping of raspberry by the addition of modified corn starch and tartaric and citric acids. It was made a central composite design $2^{3}$ and the dependent variables studied were color, brightness, texture and flavor, making a total of 20 tests. We also determined some physical and chemical characteristics of the topping. The sensory attributes were evaluated by 2400 potential consumers during the $15^{\text {th }}$ Fenadoce (Brazilian Fair of Candy) in the city of Pelotas - RS. The different acids combinations influenced on the results of the physical and chemical characteristics of the formulations tested. All formulations had excellent acceptance by consumers, who appreciated the attractive color and brightness and bittersweet flavor that contrasted with the vanilla custard, used as a vehicle. The design has established that the best combination of the independent variables tested would be citric acid 0.3 to $0.5 \%$ and modified corn starch 4\%; ensure that the desired sensory characteristics and quality of the product, enabling its marketing.
\end{abstract}

Keywords: topping of raspberry; modified corn starch; acids.

\title{
Referências
}

ANTTONEN, M. J., KARJALAINEN, R.O. Environmental and genetic variation of phenolic compounds in red raspberry. Journal of Food Composition and Analisys, v 18, p. 759-769, 2005.

ANVISA (Agência Nacional de Vigilância Sanitária). Resolução CNS/MS no 04, de 24 de novembro de 1988 . Diário Oficial da União, de 19/12/1988.

AOAC. Official methods of analysis. 13ed. Washington. DC: Association of official Analytical Chemists, 1980.

ARAÚJO, J.M.A. Química de alimentos: teoria e prática, 3 ed, Viçosa, MG: Editora UFV, 2004.

BEATTIE, J.; CROZIER, A.; DUTHIE, G.G. Potential health benefits of berries. Current Nutrition \& Food Science, v. 1, p. 71-86, 2005.

BEEKWILDER, J.; HALL, R.D.; RIC DE VOS, C.H. Identification and dietary relevance of antioxidants from raspberry, Biofactors, v. 23, p.197-205, 2005.

BURDOCK, G. A. Encyclopedia of Food and Color Additives. New York: CRC Press, v. 03, 1997.

CEREDA, M. P. Estrutura dos grânulos de amido. In: Cultura de Tuberosas Amiláceas Latino Americanas. Propriedades gerais do amido, São Paulo: Fundação Cargill, Vol. 1, p. 101-133, 2002 a. 
CEREDA, M. P. Propriedades do amido. In: Cultura de Tuberosas Amiláceas Latino Americanas. Propriedades gerais do amido, São Paulo: Fundação Cargill, Vol. 1, p. 141-185, 2002 b.

CEREDA, M. P.; VILPOUX, O.; DEMIATE, I. M. Amidos modificados. In: Cultura de Tuberosas Amiláceas Latino Americanas. Vol. 3 Tecnologia, uso e potencialidades de tuberoses amiláceas Latino Americanas, São Paulo: Fundação Cargill, p. 247-333, 2003.

CHUN, J.; LEE, J.; YE, L.; EXLER, J.; EITENMILLER, R. R. Tocopherol and tocotrienol contents of raw and processes fruits and vegetables in united states diet. Journal of Food Composition and Analisys, v 19, p. 196-204, 2006.

GARCIA-VIGUEIRA, C.; ZAFRILLA, P.; TOMÁS-BARBERÁN, F. A. Influence of processing and storage conditions in strawberry jam color. Food Science and Technology International. v. 5, p. 487-492, 1999.

GAVA, A. J. Princípios de Tecnologia de Alimentos: São Paulo, Editora Nobel, 1995.

GONÇALVES, E. D.; TREVISAN, R.; ANTUNES, L. E. C. Pequenas frutas para a região da fronteira oeste do RS, In: Seminário de fruticultura da fronteira oeste do Rio Grande do Sul. Anais, Uruguaiana, RS, 2005.

GULARTE, M.A. Manual de análise sensorial. Pelotas: Edigraf UFPel, 2002.

HAFFNER, K.; ROSENFELD, H.J; SKREDE, G.; WANG, L. Quality of red raspberry Rubus idaeus L. cultivars after storage in controlled and normal atmospheres. Postharvest Biology and Technology, v 24, p. 279-289, 2002.

LEE, H.S. Characterization of major anthocyanins and the color of red-fleshed budd blood orange (Citrus sinensis). Journal of Agricultural and Food Chemistry, v. 50, p. 1243-1246, 2002.

MATTILA, P.; HELlSTROM, J.; TÖRRÖNEN, R. Phenolic acids in berries, fruits and beverages. J. Agric. Food Chem., v 54, p. 7193-7199, 2006.

NETO, B. B.; SCARMINIO, I. S.; BRUNS, R. E. Como fazer experimentos. 3 ed. Campinas, SP: Editora da Unicamp, 480 p, 2007.

OCHOA, M.R.; KESSELER, A. G; VULliOUD, M.B.; LOZANO, J.E. Phisical and chemical characteristics of raspberry pulp: storage effect on composition and color. Lebensm.-wiss. u-Technology, v. 32, p 149-153, 1999.

PAGOT, E.; HOFFMANN, A. Produção de pequenas frutas no brasil. In: $1^{\circ}$ Seminário brasileiro sobre pequenas frutas, 2003, Vacaria/RS. Documento 37, Palestras, Embrapa Uva e Vinho. 2003. p. 7-15.

PANTELIDIS, G. E.; VASILAKAKIS, M.; MANGANARIS, G. A.; DIAMANTIDIS, Gr. Antioxidants capacity, phenol, anthocianin and ascorbic acid contents in raspberries, blackberries, red currants, gooseberries and cornelian cherries. Food Chemistry, v 102, p. 777-783, 2007.

PLESSI, M; BERTELLI, D.; ALBASINI, A. Distribution of metals and phenolics compounds as a criterion to evaluate variety of berries and related jams. Food Chemistry, v. 100, p.419-427, 2007.

RASEIRA, M.C.B.; GONÇALVES, E.D.; TREVISAN, R.; ANTUNES, L.E.C. Aspectos técnicos da cultura da framboeseira. Documentos 120, Embrapa Clima Temperado: Pelotas/RS, 24p, 2004..

RODRIGUES, S. A. Topping de mirtilo: desenvolvimento e caracterização. 2006. Dissertação (mestrado)-Programa de Pós-Graduação, Departamento de Ciência e Tecnologia Agroindustrial, Universidade Federal de Pelotas, Pelotas, 2006.

RODRIGUES, S. A.; GULARTE, M. A.; PEREIRA, E. R. B.; BORGES, C. D.; VENDRUSCOLO, C. T. Influência da cultivar nas características físicas, químicas e sensoriais de topping de mirtilo. Revista Brasileira de Tecnologia Agroindustrial. n. 1,v. 01, p 9-29, 2007.

STRIK, B. C. Berry crops: worldwide area and production systems. In: Zhao, Y. (Ed.) Berry Fruit: value-added products for health promotion, CRC press - Taylor \& Francis Group, New York, USA, p. 3-49, 2007.

TALCOTT, S. T. Chemical components of berry fruits. In: Zhao, Y. (Ed.) Berry Fruit: value-added products for health promotion, CRC press - Taylor \& Francis Group, New York, USA, p. 51-72, 2007. 
WANG, S. Y.; LIN, H. Antioxidant activity in fruits and leaves of blackberry, raspberry and strawberry varies with cultivar and developmental stage. Jounal agricultural food chemistry, v. 48, p. 140-146, 2000.

\section{Agradecimentos}

Agradecemos a FAPERGS pelo suporte financeiro e ao CNPq pela concessão da bolsa.

Dados do primeiro autor

Nome Completo: Elisabete Regina Braga Pereira

Filiação Institucional: Universidade Federal de Pelotas - UFPel

Departamento: Departamento de Ciência e Tecnologia Agroindustrial - DCTA

Função: Aluna Mestrado

Endereço completo para correspondência: Campus universitário, s/n Caixa postal 354 - Centro de Biotecnologia - Laboratório de Biopolímeros. CEP 96010-900

Telefone para contato: (53) 32757585

e-mail: beterbpereira@ig.com.br 